\title{
Immunoproteomic and mass spectrometric analysis of Eimeria acervulina antigens recognized by antisera from chickens infected with E. acervulina, E. tenella or E. necatrix
}

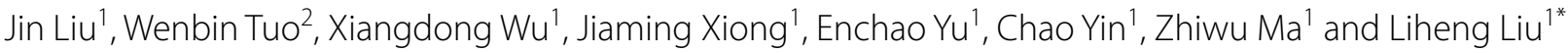

\begin{abstract}
Background: Coccidiosis is caused by Eimeria spp. and can result in severe economic losses to the global poultry industry. Due to anticoccidial drug resistance rapidly developing in the parasites and drug residues in poultry products, efficacious and safe alternative coccidia control measures are needed. The objective of the present study was to identify common protective antigens which may be used as vaccine candidates in the development of subunit, multivalent, cross-protective vaccines against most of the economically important Eimeria species.

Methods: Whole sporozoite proteins of Eimeria acervulina were prepared and analyzed by 2-dimensional gel electrophoresis (2-DE) followed by western blotting using immune sera specific to E. tenella, E. acervulina, or E. necatrix. The protein spots detected by all three immune sera were then excised from the preparative gel and protein ID was performed by MALDI-TOF-MS/MS.
\end{abstract}

Results: Approximately 620 E. acervulina sporozoite protein spots were demonstrated by 2-DE with silver staining, among which 23 protein spots were recognized by immune sera specific to all three Eimeria species. The results showed that 21 putative E. acervulina proteins were identified, which include proteins with known enzymatic properties, and those which are involved in protein translation, transport and trafficking, and ribosomal biogenesis and functions. There is one protein which may be involved in transcription and one heat-shock protein. Two proteins contain predicted domains, but with no apparent functions known. There were 2 protein spots which had no detectable proteins. None of the proteins has a predicted signal peptide or a transmembrane domain; however, 6 of the 21 putative proteins were predicted to be potentially secretory through the non-classical pathway.

Conclusions: Our study identified a diverse group of antigens immunologically common to all three Eimeria species, none of which was previously characterized and tested as a vaccine candidate. Further research on immunogenicity and cross-protective potential of these individual proteins as vaccine candidates will aid the development of vaccines against the most common and pathogenic Eimeria spp.

Keywords: Eimeria, Sporozoite, Common immunoreactive antigens, Two-dimensional gel electrophoresis (2-DE), Immunoproteomics, Mass spectrometry

\footnotetext{
*Correspondence: liulh0714@jxau.edu.cn

1 Jiangxi Provincial Key Laboratory for Animal Health, College

of Animal Science and Technology, Jiangxi Agricultural University,

Nanchang 330045, Jiangxi, People's Republic of China

Full list of author information is available at the end of the article
}

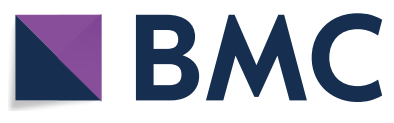

(c) The Author(s) 2020. This article is licensed under a Creative Commons Attribution 4.0 International License, which permits use, sharing, adaptation, distribution and reproduction in any medium or format, as long as you give appropriate credit to the original author(s) and the source, provide a link to the Creative Commons licence, and indicate if changes were made. The images or other third party material in this article are included in the article's Creative Commons licence, unless indicated otherwise in a credit line to the material. If material is not included in the article's Creative Commons licence and your intended use is not permitted by statutory regulation or exceeds the permitted use, you will need to obtain permission directly from the copyright holder. To view a copy of this licence, visit http://creativecommons.org/licenses/by/4.0/. The Creative Commons Public Domain Dedication waiver (http://creativecommons.org/publicdomain/zero/1.0/) applies to the data made available in this article, unless otherwise stated in a credit line to the data. 


\section{Background}

Poultry coccidiosis is an intestinal disease caused by the protozoan parasites of the genus Eimeria [1]. It has been estimated that coccidiosis can cause more than $€ 2$ billion in annual losses to the global poultry industry [2]. The infection in chickens usually results in intestinal bleeding, reduced feed conversion, weight loss, and even death in severe cases [3]. Eimeria species have a complicated life-cycle with 3 major stages: schizogony, gametogony and sporulation [4]. It has been well documented that there are multiple pathogenic Eimeria species, including E. necatrix, E. tenella and E. acervulina $[5,6]$; thus, they are the focus of the present study.

The current control methods of poultry coccidiosis primarily rely on the use of anti-coccidian drugs and/ or live attenuated vaccines $[7,8]$. However, there are two main problems with these methods, the emergence of drug resistant strains and drug residues in poultry products [9]. The current use of the live attenuated Eimeria strains as vaccines still has to face the risk of residual pathogenesis to the birds, reversion to pathogenic forms and high cost of producing and maintaining the live vaccines for the manufacturers and producers. Therefore, subunit coccidiosis vaccines, produced using recombinant DNA technology and having the advantage of being safe, cost-effective and efficacious, are urgently needed. In recent years, DNA-based vaccines against coccidiosis have been reported with some protection [10-14]. However, it is well known that field coccidiosis is often caused by co-infections with multiple pathogenic strains of Eimeria $[15,16]$. Hence, it is necessary to develop a vaccine that cross-protects the chickens from most of the pathogenic strains of Eimeria.

Proteomics has been successfully performed to study and identify drug targets in parasites [17, 18]. Furthermore, immunoproteomics has been used to identify the antigens of Eimeria origin. de Venevelles et al. [19] performed immunoproteomics on identification of immunoreactive proteins in E. tenella sporozoites, which resulted in discovery of approximately 50 , out of a total of 130 , proteins recognized by anti-E. tenella sera. Twodimensional gel electrophoresis (2-DE) and western blotting were used to analyze the second-generation merozoite proteins of E. tenella, where approximately 640 proteins were demonstrated on the proteome map and 85 of them were recognized by the anti-E. tenella sera [20]. In addition, Zhang et al. [21] also conducted immunoproteomics studies with Eimeria antigens and identified 46 proteins as antigens of the unsporulated $E$. tenella oocysts.

In the present study, whole sporozoite proteins of $E$. acervulina were prepared and analyzed by $2-\mathrm{DE}$ and western blotting. Eimeria acervulina protein spots recognized by anti-sera against $E$. tenella, E. acervulina, and $E$. necatrix were collected and analyzed for protein ID by mass spectrometry. A total of 620 E. acervulina sporozoite protein spots were identified by $2-\mathrm{DE}$ and silver staining, 21 of which were identified as antigens immunoreactive to hyperimmune sera of all three species of Eimeria. These 21 immunologically common proteins are putative, uncharacterized previously and highly diverse in cellular locations and predicted functions. Further research on these shared antigens may lead to the development of cross-protective, multivalent vaccines against coccidiosis.

\section{Methods \\ Animals}

One-day-old San Huang chicks (Wenzhen Hatchery, Nanchang, China) were raised under coccidia-free conditions before the infection experiments.

\section{Parasites}

Oocysts of E. acervulina, E. necatrix and E. tenella (Nanchang strains) were stored in our laboratory. Oocysts of the three Eimeria species were propagated, harvested and sporulated as reported previously [22, 23]. The sporulated oocysts were stored in $2.5 \%(\mathrm{w} / \mathrm{v})$ potassium dichromate solution at $4{ }^{\circ} \mathrm{C}$ no longer than 2 weeks. Sporozoite isolation was conducted, as described previously, using a DE-52 anion exchange column for purification [24]. The purified sporozoites were stored in liquid nitrogen before use.

\section{Protein sample preparation}

The purified sporozoites of the E. acervulina were suspended with lysis buffer [7 M urea, $2 \mathrm{M}$ thiourea, $4 \%$ (w/v) CHAPS, 1\% (w/v) DTT, 1\% protease inhibitor cocktail $(\mathrm{v} / \mathrm{v})$ and $2 \%(\mathrm{v} / \mathrm{v})$ immobilized $\mathrm{pH}$ gradient buffer] and sonicated in ice bath $(200 \mathrm{~W}$, work time $6 \mathrm{~s}$, interval time $15 \mathrm{~s}$, for 60 cycles). Soluble proteins were obtained after centrifugation at $15,000 \times \mathrm{rpm}$ for $10 \mathrm{~min}$ at $4{ }^{\circ} \mathrm{C}$. The supernatants were treated with a 2-D cleanup kit and protein concentrations were quantified using PlusOne $^{\mathrm{TM}}$ 2-D Quant Kit (GE Healthcare Life Sciences, Pittsburgh, PA, USA) [20, 25].

\section{Two-dimensional gel electrophoresis (2-DE) Isoelectric focusing (IEF)}

IEF was performed as previously reported [20, 26]. To achieve increased separation of proteins, $24 \mathrm{~cm}$ IPG strips (pH 3-10, non-linear; GE Healthcare Life Sciences) 
were used for IEF. Briefly, the protein preparation was mixed with immobilized $\mathrm{pH}$ gradient (IPG) rehydration/sample buffer [8 $\mathrm{M}$ urea, 2\% CHAPS, $20 \mathrm{mM}$ DTT, $0.5 \%$ (v/v) IPG buffer, pH 3-10, and 0.001\% bromophenol blue] and incubated for at least $1 \mathrm{~h}$ at room temperature. Sporozoite proteins $(200 \mu \mathrm{g})$ were loaded onto an IPG strip followed by rehydration for $12 \mathrm{~h}$ at $20^{\circ} \mathrm{C}$ by using rehydration buffer. IEF was performed using preset programs on EttanIgphor II (GE Healthcare Life Sciences) in 4 steps: $\mathrm{S} 1$ at $0-50 \mathrm{~V}$ for $12 \mathrm{~h} ; \mathrm{S} 2$ at $50-8000 \mathrm{~V}$ for $4 \mathrm{~h}$; S3 at $8000-10000 \mathrm{~V}$ for $4 \mathrm{~h}$; and $\mathrm{S} 4$ at $10000 \mathrm{~V}$ for $4 \mathrm{~h}$.

\section{Sodium dodecyl sulphate polyacrylamide gel electrophoresis (SDS-PAGE)}

Prior to SDS-PAGE, the gel strips were incubated in equilibration buffer I (50 mM Tris- $\mathrm{HCl}, \mathrm{pH} 8.8,6 \mathrm{M}$ urea, 2\% SDS, 30\% glycerol and 1\% DTT) for $15 \mathrm{~min}$ and then in equilibration buffer II $(50 \mathrm{mM}$ Tris- $\mathrm{HCl}, \mathrm{pH}$ 8.8, $6 \mathrm{M}$ urea, $2 \%$ SDS, $30 \%$ glycerol and $2.5 \%$ iodoacetamide) for $15 \mathrm{~min}$. The strips and SDS-PAGE molecular weight standards (11-180 kDa; Thermo Fisher Scientific, Waltham, MA, USA) were then loaded onto the $12.5 \%$ polyacrylamide gels [21]. Each sample was simultaneously run on 2 separate gels, one was used for western blotting, the other was used for silver staining, according to the methods reported previously [27]. ArtixScan 1010 Plus (Microtek International, Inc., Taiwan, China) was used for imaging gels.

\section{Analysis of images}

The stained gels were analyzed using the ImageMaster ${ }^{\mathrm{TM}}$ 2D Platinum Software (Version 5.0, GE Healthcare, San Francisco, CA, USA) for protein spot detection, quantification and matching as well as comparative and statistical analyses [26].

\section{Antiserum preparation}

Chickens were raised coccidia-free until 2 weeks-old, and then divided into 4 groups $(n=30)$ and housed in 4 separate rooms. Three groups were orally infected with sporulated oocysts of E. tenella, E. acervulina or E. necatrix. The dose of first infection was $1 \times 10^{5}$ sporulated oocysts per chicken [28]. Three days after the first infection, the chickens were infected 4 more times, at 3-day intervals, at a dose of 5000 sporulated oocysts per chicken. The remaining group of chickens was used as negative control, and inoculated by gavage with distilled water only. Five weeks after the last infection, blood samples were obtained from chicken's wing vein, coagulated for $1 \mathrm{~h}$ at $37{ }^{\circ} \mathrm{C}$, and then incubated overnight at $4{ }^{\circ} \mathrm{C}$. After centrifugation at $4000 \times \mathrm{rpm}$ for $10 \mathrm{~min}$, the serum was collected, aliquoted, and stored at $-20{ }^{\circ} \mathrm{C}$ until used [29]. Specific antibody titers were determined in 2 -fold serial dilutions by ELISA using E. acervulina sporozoite antigens. All sera used in this study had ELISA titers of 1280 or higher.

\section{Western blot}

To increase transfer efficiency, each gel was cut into 4 equal pieces prior to transfer. Proteins were transferred to a polyvinylidene fluoride (PVDF) membrane of $0.45 \mu \mathrm{m}$ pore size (GE Healthcare). Membranes were blocked with $5 \%$ non-fat-dried milk in phosphate-buffered saline (PBS) ( $\mathrm{pH}$ 7.4) containing 0.05\% Tween 20 (PBST) for $2 \mathrm{~h}$ at room temperature with shaking. Membranes were then incubated with one of the hyper-immune sera (1:100) for $2 \mathrm{~h}$ at room temperature. The pooled uninfected chicken sera were used as a negative control. After washing with PBST, the membrane was incubated with a secondary reagent (1:2000, donkey anti-chicken IgY conjugated with horseradish peroxidase; Proteintech Group, Inc., Rosemond, IL, USA) for $2 \mathrm{~h}$ at $37{ }^{\circ} \mathrm{C}$. The membranes were washed with PBST for $1 \mathrm{~h}$ and developed with an enhanced chemiluminescence detection kit (GE Healthcare Life Sciences). The ChemiDoc ${ }^{\mathrm{TM}}$ XRS + with Image $\mathrm{Lab}^{\mathrm{TM}}$ Software (Bio-Rad, Hercules, CA, USA) was used for imaging and image analysis [26].

\section{Mass spectrometric (MS) analysis of protein spots, database search and protein sequence analysis}

As previously reported, protein spots were removed from the SDS-PAGE gel and subjected to trypsin digestion and desalination [30]. MS analysis of protein spots was performed by the Experimental Center of Nanjing Medical University (Nanjing, China). MS and MS/MS data for protein ID were obtained by using a MALDITOF-TOF instrument (Bruker Daltonics, Bremen, Germany). The database search was conducted against the non-redundant protein sequences (nr) of NCBI (NCBInr) using the Mascot search engine (http://www.matrixscie nce.com). The search parameters included taxonomy of other Alveolata, one missed trypsin cleavage site allowed, fixed modifications of carbamidomethyl (C), variable modifications of oxidation (M), 100 parts per million mass accuracy, and MS/MS fragment tolerance set to 0.4 Da. The results of the search were considered positive if Mascot score of a protein is greater than $71(P<0.05)$ and sequence coverage is more than $15 \%$ with at least 4 matching peptides [31]. Protein orthologs within the three species of Eimeria were further compared for sequence identity using the multiple sequence alignment program CLUSTAL Omega (https://www.ebi.ac.uk/Tools $/ \mathrm{msa} /$ clustalo/). Non-classical secretory property (SecP) and presence of a signal peptide (SP) and transmembrane domains were analyzed by the SecretomeP 2.0a 
Server (http://www.cbs.dtu.dk/services/SecretomeP/), SignalP-5.0 Server (http://www.cbs.dtu.dk/services/Signa $\mathrm{IP} /$ ) and TMHMM Server v. 2.0 (http://www.cbs.dtu.dk/ services/TMHMM/), respectively.

\section{Results}

\section{Eimeria acervulina sporozoite protein 2-DE profile}

Analysis by 2-DE followed by silver staining revealed 620 protein spots in the soluble proteins of $E$. acervulina sporozoites. Most protein spots were located between 11 and $180 \mathrm{kDa}$ (Fig. 1).

\section{Detection of common immunoreactive spots by western blot using immune sera from the three Eimeria spp}

Western blot analysis of 2-DE-separated E. acervulina sporozoite proteins using 3 individual immune sera showed that 118 protein spots were recognized by antiE. acervulina serum, 92 protein spots were recognized by anti-E. necatrix serum, and 102 protein spots were recognized by anti-E. tenella serum. There was a total of 23 immunoreactive protein spots recognized by all three anti-Eimeria sera (Fig. 2, Table 1). No immunoreactive protein spots were detected by sera from negative control chickens (Fig. 3).

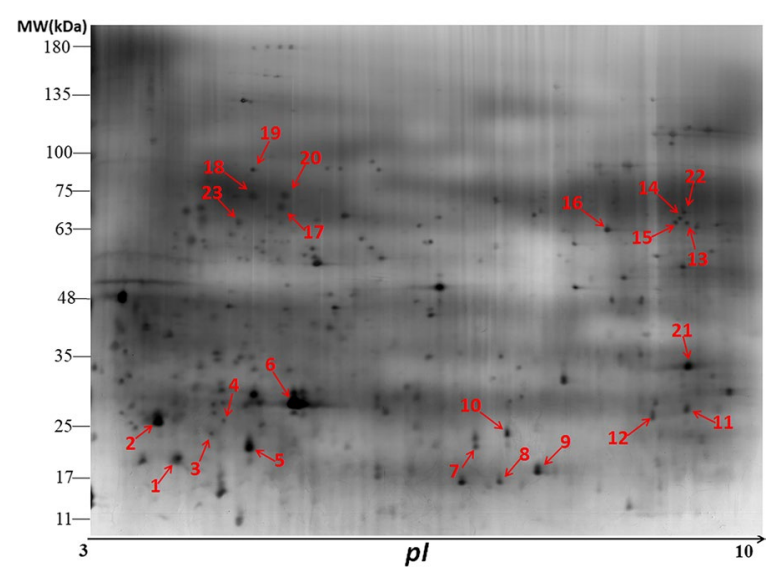

Fig. 1 Eimeria acervulina sporozoite protein 2-dimensional gel electrophoresis (2-DE) profile demonstrated by silver staining. The soluble sporozoite proteins $(200 \mu \mathrm{g})$ of E. acervulina were first resolved by isoelectric focusing (IEF) using a $24 \mathrm{~cm}$ immobilized pH gradient (IPG) strip ( $\mathrm{pH} 3-10)$. Then, sodium dodecyl sulfate polyacrylamide gel electrophoresis (SDS-PAGE) (12.5\%) was used to separate the proteins by size followed by silver staining. The $Y$-axis shows the protein $\mathrm{Mr}$. range between 11 and $180 \mathrm{kDa}$ and $\mathrm{X}$-axis indicates the protein pl range between 3 and 10. Data represent results from 2 independent experiments
Protein identification and sequence analysis of the antigens recognized by immune sera specific to all three species of Eimeria

Peptide mass-fingerprinting (PMF) data of 23 protein spots were obtained by analysis with MALDI-TOFMS/MS. The PMF data were then searched against the NCBInr using the Mascot search engine. Twenty-one Eimeria proteins with shared immunogenicity identified from protein spots 1 through 21 are summarized in Table 1. There were additional 2 spots (spots 22, 23) which were recognized by all three Eimeria sera (Figs. 1, 2), but no protein signals were detected (data not shown). The results showed that all the proteins identified in this study met the three criteria in that Mascot score is greater than 71 , sequence coverage is more than $15 \%$, and there are at least 4 matching peptides for each protein identified. In addition, sequence identity for the protein orthologs in all three Eimeria species, protein secretory property, and presence of signal peptides and transmembrane domains were analyzed and the results are summarized in Table 2.

\section{Discussion}

Identifying and testing common antigens as vaccine candidates across various Eimeria species is an immune response-based approach in the development of subunit vaccines against coccidiosis [32]. The advantage of using a cross-protective subunit vaccine is relatively safe, cost-effective, and labor-saving. Researchers have previously explored the common antigens of Eimeria species. Talebi [33] discovered at least one conserved protein band ( $45 \mathrm{kDa}$ ) from five Eimeria species (E. acervulina, E. maxima, E. necatrix, E. praecox and E. tenella), which was recognized by anti-E. maxima serum. Constantinoiu et al. [34] found that the apical complex of six species of Eimeria sporozoites (E. brunetti, E. mitis, E. maxima, E. necatrix, E. praecox and $E$. tenella) could be recognized by the monoclonal antibody $8 \mathrm{E}-1$ using immunofluorescence analysis. Liu et al. [29] identified immunodominant proteins of three Eimeria species (E. tenella, E. maxima and $E$. acervulina), in which five groups of the protein orthologs were detected as common antigens. The $E$. acervulina 14-3-3 antigen was shown to induce significant immune responses and provided protection against E. tenella, E. acervulina and E. maxima infection [35]. The results of the present study added more putative, common, immunoreactive proteins to the list of crossprotective antigens, which should aid in facilitating the development of multivalent vaccines against co-infections by pathogenic Eimeria species.

The present study identified a group of proteins which are highly diverse in predicted cellular localizations and 

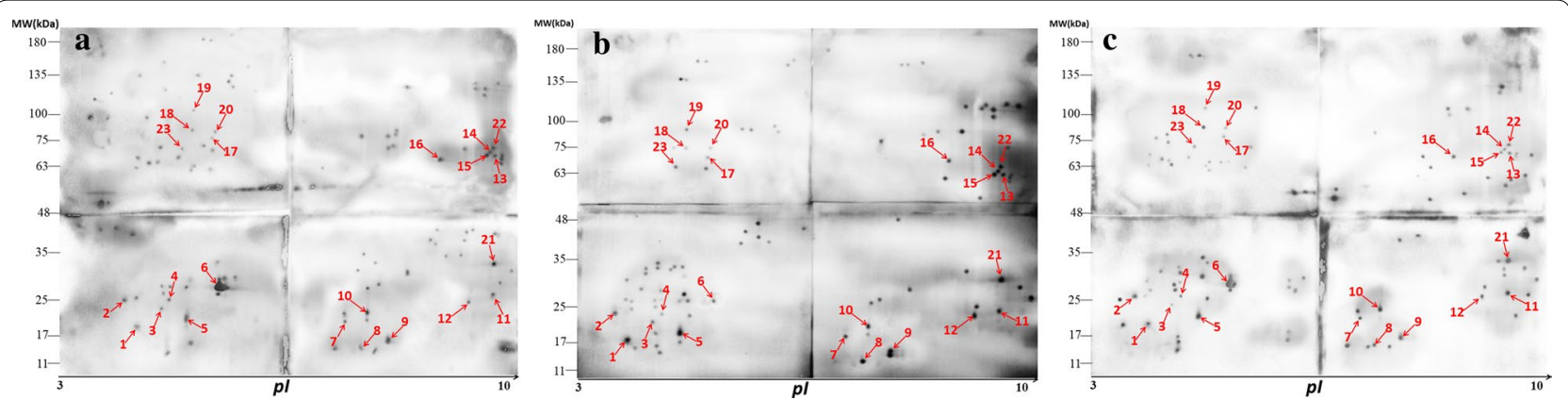

Fig. 2 Detection of Eimeria acervulina sporozoite antigens separated with 2-dimensional gel electrophoresis (2-DE) by western blot using chicken anti-E. acervuline (a), anti-E. necatrix (b), or anti-E. tenella (c) sera. The proteins recognized by chicken immune sera against all three Eimeria species are indicated. Data represent results from 2 independent experiments

functions. Comparison of the amino acid sequences of orthologs showed that some antigens have moderate amino acid sequence conservation (spots 1,3,4 and 19). We speculate that, while most of the 21 common antigens may have both linear and conformational epitopes, some may reply heavily on conformational epitopes due to limited selections/availability of linear epitopes. Further, the lack of sequence identity may also be caused by incomplete protein sequences. Additional work is warranted to further confirm the correct annotation of the orthologs which appear to have large variations, having less than $50 \%$ in sequence identity with at least one of the three species in the genus (spots 1, 3, 4 and 19). No signal peptides or transmembrane domains were predicted from all 21 proteins, suggesting that none of the proteins are membrane-bound proteins or secretory proteins through the classical secretory pathway. Indeed, six proteins were predicted to be potentially secreted via the non-classical secretory pathway.

Only 1-2 proteins were identified in each of the following categories, including those with functions in protein translation, RNA transcription, cargo/protein transport and trafficking, ribosome function and biogenesis, and chaperone (heat-shock protein). Interestingly, immunization with the translation elongation factor EF-2 identified by 2-DE and MALDI in Brugia malayi adult worm protected the host from challenge infection with thirdstage larvae [36]. Furthermore, a study using malariaprotective IgG identified a member of the heat-shock protein family, the eukaryotic translation initiation factor 3 , and a ribosome-associated protein, which were considered vaccine candidates [37]. The only transcription factor identified in the present study was elongin $C$, which is essential for viral pathogenesis and replication, but there is no evidence that this protein may play a key role in protozoan pathogenesis [38]. Very little information is available about protozoan ribosome-related and HSP proteins demonstrated in this study.

The most striking finding of the present study is that 11 out of the 21 immunologically related antigens in all three Eimeria species are proteins of known enzymatic activities. In addition, five out of the 11 proteins with predicted enzymatic functions had been shown in other species that they can be vaccine candidates. These five proteins include glycerol-3-phosphate dehydrogenase (GPD, XP_013248247.1), protein phosphatase 2C (PP2C, XP_013248554.1), glyceraldehyde-3-phosphate dehydrogenase (GAPDH, XP_013251305.1), cysteine desulfurase (CDS, XP_013251976.1), and glyoxalase (GLO, XP_013247421.1). Candida albicans surface protein GPD binds to complement regulators for immune evasion by inactivating the complement cascade [39]. Toxoplasma gondii, an apicomplexan protozoan parasite, PP2C was identified as one of the highly upregulated genes in vivo by screening the $T$. gondii cDNA phage expression library using specific IgM and IgG [39]. The presence of upregulated immunogenic PP2C suggests that PP2C is a potential vaccine candidate for toxoplasmosis [40]. As a common antigen of Eimeria, GAPDH could induce strong humoral and cellular immune responses, and had effective protection against $E$. tenella, $E$. acervulina and E. maxima as a potential vaccine candidate [41]. In our present study, GAPDH as an immunodominant antigen was confirmed to be immunologically shared by all three Eimeria species. An epitope (a peptide called P39) of the GAPDH was identified on the Plasmodium sporozoite surface, and Plasmodium GAPDH was shown to bind to CD68 on the Kupffer cells [42]. Furthermore, the antibody to P39 suppressed sporozoite liver invasion without cross-recognizing host GAPDH [42]. In a study of bacterial surface proteomics, cysteine desulfurase, traditionally an intracellular protein, was identified on the bacterial cell surface. This protein and others characterized in that 
Table 1 Immunoproteomic and mass-spectrometric identification of Eimeria acervulina sporozoite proteins recognized by immune sera of the three Eimeria species studied

\begin{tabular}{|c|c|c|c|c|c|c|}
\hline Spot IDa & Identified protein grouped by functions & Accession number ${ }^{b}$ & $\begin{array}{l}\text { No. of } \\
\text { matched } \\
\text { peptides }\end{array}$ & Theoretical Mr/pl & Protein score $^{d}$ & $\begin{array}{l}\text { Protein } \\
\text { sequence } \\
\text { coverage (\%) }\end{array}$ \\
\hline \multicolumn{7}{|c|}{ Protein translation } \\
\hline 1 & Elongation factor 1-beta, putative, partial & XP_013248731.1 & $16 / 40$ & $19289 / 4.51$ & 209 & 62 \\
\hline 6 & $\begin{array}{l}\text { Eukaryotic translation initiation factor } 3 \text { subunit } 8 \text {, } \\
\text { putative }\end{array}$ & XP_013250573.1 & $14 / 37$ & $31924 / 9.76$ & 172 & 55 \\
\hline \multicolumn{7}{|c|}{ Transcription } \\
\hline 8 & Elongin c, putative & XP_013249709.1 & $11 / 47$ & $17120 / 5.34$ & 144 & 49 \\
\hline \multicolumn{7}{|c|}{ Cargo transport and protein trafficking } \\
\hline 2 & $\begin{array}{l}\text { Intraflagellar transport particle protein, putative, } \\
\text { partial }\end{array}$ & XP_013246990.1 & $16 / 46$ & $28884 / 8.35$ & 220 & 43 \\
\hline 9 & AP-4 complex subunit sigma-1, putative & XP_013248843.1 & $11 / 33$ & $17189 / 5.41$ & 135 & 40 \\
\hline \multicolumn{7}{|c|}{ Ribosome-related proteins } \\
\hline 7 & $60 S$ ribosomal protein $L 8$, putative & XP_013249139.1 & $12 / 40$ & $28042 / 10.71$ & 120 & 37 \\
\hline 18 & Ribosome biogenesis protein brix, putative & XP_013248150.1 & $17 / 54$ & $54150 / 9.82$ & 170 & 38 \\
\hline \multicolumn{7}{|c|}{ Predicted domain-containing proteins } \\
\hline 3 & $\begin{array}{l}\text { Uncharacterized ACR, YagE family COG1723 } \\
\text { domain-containing protein, putative }\end{array}$ & XP_013250980.1 & $18 / 45$ & 20048/9.58 & 240 & 49 \\
\hline 4 & U1 like $\mathrm{C} 2 \mathrm{H} 2$ zinc finger, related & XP_013248237.1 & $14 / 35$ & $28894 / 9.60$ & 199 & 68 \\
\hline \multicolumn{7}{|c|}{ Chaperone proteins } \\
\hline 17 & DnaJ domain-containing protein, putative & XP_013253345.1 & $15 / 49$ & $48311 / 6.56$ & 140 & 36 \\
\hline \multicolumn{7}{|c|}{ Protein of enzymatic properties } \\
\hline 5 & Nucleolar GTP-binding protein, putative & XP_013252320.1 & $11 / 41$ & $21119 / 9.70$ & 147 & 57 \\
\hline 10 & $\begin{array}{l}\text { Glycerol-3-phosphate dehydrogenase, putative, } \\
\text { partial }\end{array}$ & XP_013248247.1 & $17 / 31$ & $35465 / 6.67$ & 237 & 60 \\
\hline 11 & Protein phosphatase $2 \mathrm{C}$, putative & XP_013248554.1 & $13 / 56$ & $42702 / 5.82$ & 116 & 28 \\
\hline 12 & $\begin{array}{l}\text { Glyceraldehyde-3-phosphate dehydrogenase, } \\
\text { putative }\end{array}$ & XP_013251305.1 & $16 / 46$ & $36753 / 7.57$ & 211 & 41 \\
\hline 13 & Cysteine desulfurase, putative & XP_013251976.1 & $17 / 34$ & $63362 / 8.43$ & 191 & 45 \\
\hline 14 & Glyoxalase, putative & XP_013247421.1 & $20 / 39$ & $65222 / 6.63$ & 246 & 37 \\
\hline 15 & Phosphatase, putative & XP_013251081.1 & $14 / 38$ & $62536 / 9.36$ & 158 & 34 \\
\hline 16 & Phosphoribosylpyrophosphate synthetase, putative & XP_013248652.1 & $17 / 40$ & $47500 / 9.30$ & 171 & 57 \\
\hline 19 & CAM kinase, CDPK family TgPK1, putative & XP_013250395.1 & $15 / 36$ & $118100 / 7.12$ & 134 & 16 \\
\hline 20 & DNA photolyase, putative & XP_013251340.1 & $14 / 31$ & $52839 / 8.79$ & 147 & 37 \\
\hline 21 & gamma-glutamyl phosphate reductase, putative & XP_013252670.1 & $12 / 34$ & $44087 / 5.46$ & 153 & 36 \\
\hline
\end{tabular}

a Protein spot numbering in the 2-DE gel; spots 22 and 23 that had no detectable protein signals are not listed

b Accession number in NCBI

c Number of peptides that match the predicted protein sequence

d Protein score is $-10^{*} \log (P)$, where $P$ is the probability that the observed match is a random event. Protein scores greater than 71 are significant $(P<0.05)$

e Percentage of predicted protein sequence covered by matched peptides

study were collectively named as "moonlighting proteins", indicating that intracellular proteins found on cell surface are not as rare as we may anticipate [43]. A putative Mycobacterium tuberculosis glyoxalase was identified as an intracellular and a secretory protein and high percentage of human patients had anti-glyoxalase antibodies [43]. Most importantly, the increased levels of glyoxalase and the immunoregulatory cytokine interleukin-10 in serum positively correlates, suggesting that glyoxalase can be a potential vaccine target [44]. The other five proteins in the same group had little information available, and thus, it is difficult to estimate their potential as vaccine candidates. However, based on the reported findings that many nuclear or intracellular proteins are "moonlighting" on the cell surface or being secreted to the outside of the cells, the proteins common to all three Eimeria species that stimulated antibody responses should be considered potential vaccine targets [45, 46]. Ongoing 


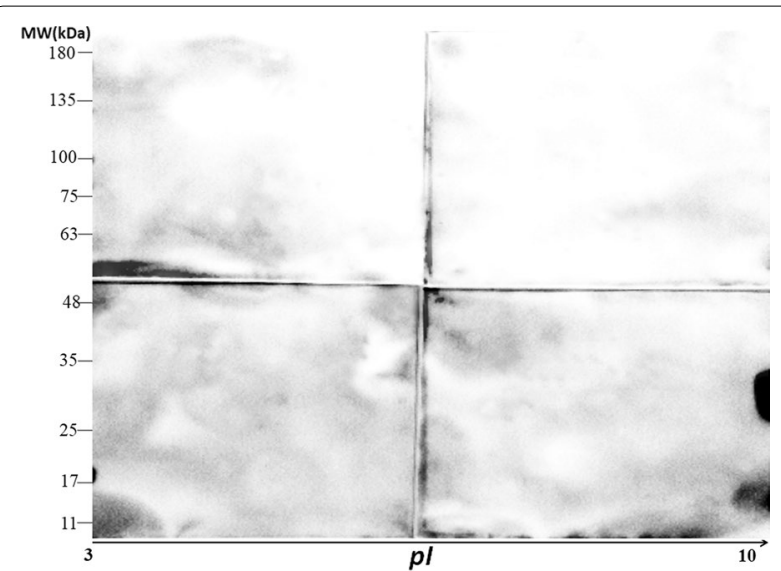

Fig. 3 Western blot analysis of the 2-dimensional gel electrophoresis (2-DE)-separated Eimeria acervulina sporozoite antigens using pooled sera from negative control chickens. The control chickens were age-matched to those infected by Eimeria and raised separately under identical conditions. Data represent results from 3 independent experiments research is testing for protective efficacies of the proteins identified in the present study, with formulations of either single protein vaccines or multivalent vaccines. The present study represents the first to show E. acervulina antigens recognized by sera specific to $E$. acervulina as well as those specific to E. tenella or E. necatrix. Interestingly, most of the E. acervulina proteins with shared immunogenicity identified in the present study were not found in a similar study where anti-E. acervulina sera were used to detect E. acervulina antigens [30]. One apparent difference between the studies is that we used antisera with much higher titers (1:1280), which could in part account for why the proteins identified in our study are not shown in the study by Liu et al. [30]. Future research is warranted to compare Eimeria antigens identified under similar experimental conditions.

Table 2 Eimeria protein amino acid sequence comparison

\begin{tabular}{|c|c|c|c|c|c|}
\hline \multirow[t]{2}{*}{ Spot IDa } & \multirow[t]{2}{*}{ Accession number } & \multicolumn{3}{|c|}{ Amino acid sequence identity $(\%)^{b}$} & \multirow[t]{2}{*}{ SecP/SP/TM prediction } \\
\hline & & E. acervulina & E. tenella & E. necatrix ${ }^{\mathrm{d}}$ & \\
\hline 1 & XP_013248731.1 & 100 & 58.72 & 44.88 & $0.053 / \mathrm{N} / \mathrm{N}$ \\
\hline 2 & XP_013246990.1 & 100 & 51.65 & 52.07 & $0.656^{*} / \mathrm{N} / \mathrm{N}$ \\
\hline 3 & XP_013250980.1 & 100 & 38.95 & 41.18 & $0.068 / \mathrm{N} / \mathrm{N}$ \\
\hline 4 & XP_013248237.1 & 100 & 48.54 & 48.71 & $0.371 / \mathrm{N} / \mathrm{N}$ \\
\hline 5 & XP_013252320.1 & 100 & 75.00 & - & $0.533 / \mathrm{N} / \mathrm{N}$ \\
\hline 6 & XP_013250573.1 & 100 & 75.19 & 75.19 & $0.843^{*} / \mathrm{N} / \mathrm{N}$ \\
\hline 7 & XP_013249139.1 & 100 & 95.14 & 94.33 & $0.462 / \mathrm{N} / \mathrm{N}$ \\
\hline 8 & XP_013249709.1 & 100 & 61.07 & 62.09 & $0.798^{*} / \mathrm{N} / \mathrm{N}$ \\
\hline 9 & XP_013248843.1 & 100 & 89.58 & 85.42 & $0.435 / \mathrm{N} / \mathrm{N}$ \\
\hline 10 & XP_013248247.1 & 100 & 73.67 & 73.35 & $0.42 / \mathrm{N} / \mathrm{N}$ \\
\hline 11 & XP_013248554.1 & 100 & 50.00 & 51.80 & $0.662^{*} / \mathrm{N} / \mathrm{N}$ \\
\hline 12 & XP_013251305.1 & 100 & 94.10 & 92.63 & $0.635^{*} / \mathrm{N} / \mathrm{N}$ \\
\hline 13 & XP_013251976.1 & 100 & 66.54 & 66.73 & $0.404 / \mathrm{N} / \mathrm{N}$ \\
\hline 14 & XP_013247421.1 & 100 & 58.44 & 60.60 & $0.245 / \mathrm{N} / \mathrm{N}$ \\
\hline 15 & XP_013251081.1 & 100 & 80.95 & 81.28 & $0.172 / \mathrm{N} / \mathrm{N}$ \\
\hline 16 & XP_013248652.1 & 100 & 84.56 & 89.52 & $0.799 * / N / N$ \\
\hline 17 & XP_013253345.1 & 100 & 96.00 & 96.00 & $0.283 / \mathrm{N} / \mathrm{N}$ \\
\hline 18 & XP_013248150.1 & 100 & 61.90 & 62.67 & $0.423 / \mathrm{N} / \mathrm{N}$ \\
\hline 19 & XP_013250395.1 & 100 & 61.68 & 47.85 & $0.298 / \mathrm{N} / \mathrm{N}$ \\
\hline 20 & XP_013251340.1 & 100 & 58.02 & 59.36 & $0.376 / \mathrm{N} / \mathrm{N}$ \\
\hline 21 & XP_013252670.1 & 100 & 67.26 & 67.51 & $0.454 / \mathrm{N} / \mathrm{N}$ \\
\hline
\end{tabular}

a 2-dimensional gel electrophoresis (2-DE) gel spot number

${ }^{\mathrm{b}}$ All protein sequences within the same row are compared to that of E. acervulina using CLUSTAL Omega (https://www.ebi.ac.uk/Tools/msa/clustalo/)

c Non-classical secretory property (SecP) and presence of a signal peptide (SP) and transmembrane domains (TM) were analyzed by the SecretomeP 2.0a Server (http://www.cbs.dtu.dk/services/SecretomeP/), SignalP-5.0 Server (http://www.cbs.dtu.dk/services/SignalP/) and TMHMM Server v. 2.0 (http://www.cbs.dtu.dk/servi ces/TMHMM/), respectively

d Eimeria necatrix ortholog for XP_013252320.1 was not found

Abbreviations: *, a SecP score exceeds the threshold (0.6), indicative of a secretory potential through the non-classical pathway for proteins with no signal peptides; $\mathrm{N}$ not present 


\section{Conclusions}

In this study, whole sporozoite proteins of $E$. acervulina were prepared and analyzed by 2-DE and western blotting. Eimeria acervulina protein spots recognized by three individual anti-sera against E. tenella, E. acervulina or E. necatrix were characterized. Twenty three out of 620 sporozoite protein spots were identified and 21 immunoreactive antigens common to all three species of Eimeria were identified, none of which was previously characterized and tested as vaccine candidates. Further research on immunogenicity and cross-protective potential of these individual proteins will aid in development of vaccines against the most common and pathogenic Eimeria spp.

\section{Abbreviations}

2-DE: two-dimensional gel electrophoresis; MALDI-TOF-MS/MS: matrix-assisted laser desorption/ionization-time of flight-mass spectrometry/mass spectrometry; IPG: immobilized pH gradient; SDS-PAGE: sodium dodecyl sulphate polyacrylamide gel electrophoresis; MS: mass spectrometry; PMF: peptide mass fingerprinting; IEF: isoelectric focusing; GPD: glycerol-3-phosphate dehydrogenase; GAPDH: glyceraldehyde-3-phosphate dehydrogenase; CDS: cysteine desulfurase; GLO: glyoxalase; PP2C: protein phosphatase 2C.
\end{abstract}

\section{Acknowledgements}

We are grateful to the insightful discussions on the project with Drs Hyun Lillehoj and Charles Li.

\section{Authors' contributions}

LL and WT conceived and designed the experiments. JL, XW, JX, EY, CY and ZM performed the experiments. WT, LL and JL analyzed the data. JL and WT wrote and revised the manuscript. All authors read and approved the final manuscript.

\section{Funding}

This work was funded by Grants from the National Natural Science Foundation of China (Grant No. 31560691), the Natural science foundation of Jiangxi Province (Grant No. 20151BAB204017), and the Science and Technology Research Project, Jiangxi Provincial Department of Education (Grant No. GJJ14291). The funders had no role in study design, data collection and analysis, decision to publish, or preparation of the manuscript.

\section{Availability of data and materials}

The datasets supporting the findings of this article are included within the article. The mass spectrometry proteomics data have been deposited to the ProteomeXchange Consortium via the PRIDE partner repository (http://www. ebi.ac.uk/pride) with the dataset identifier PXD016418.

\section{Ethics approval and consent to participate}

All the procedures were conducted following the guidelines of the Committee of Experimental Animals established by the Ministry of Agriculture of China. All animals were handled in strict accordance with good animal practice. The animal protocol for this study (Protocol number P-2018-04) was approved by the Animal Ethics Committee of Jiangxi Agricultural University, Nanchang, China.

\section{Consent for publication}

Not applicable.

\section{Competing interests}

The authors declare that they have no competing interests.

\section{Author details}

1 Jiangxi Provincial Key Laboratory for Animal Health, College of Animal Science and Technology, Jiangxi Agricultural University, Nanchang 330045,
Jiangxi, People's Republic of China. ${ }^{2}$ Animal Parasitic Diseases Laboratory, Agricultural Research Service, United States Department of Agriculture, Beltsville, MD 20705, USA.

Received: 1 October 2019 Accepted: 13 February 2020

Published online: 21 February 2020

\section{References}

1. Dalloul RA, Lillehoj HS. Poultry coccidiosis: recent advancements in control measures and vaccine development. Expert Rev Vaccines. 2006:5:143-63.

2. Shirley MW, Smith AL, Tomley FM. The biology of avian Eimeria with an emphasis on their control by vaccination. Adv Parasitol. 2005;60:285-330.

3. Wang P, Gong P, Wang W, Li J, Ai Y, Zhang X. An Eimeria acervulina OTU protease exhibits linkage-specific deubiquitinase activity. Parasitol Res. 2019:118:47-55.

4. Chapman HD, Barta JR, Blake D, Gruber A, Jenkins M, Smith NC, et al. A selective review of advances in coccidiosis research. Adv Parasitol. 2013;83:93-171.

5. Blake DP, Tomley FM. Securing poultry production from the ever-present Eimeria challenge. Trends Parasitol. 2014;30:12-9.

6. Reid AJ, Blake DP, Ansari HR, Billington K, Browne HP, Bryant J, et al. Genomic analysis of the causative agents of coccidiosis in domestic chickens. Genome Res. 2014;24:1676-85.

7. Sharman PA, Smith NC, Wallach MG, Katrib M. Chasing the golden egg: vaccination against poultry coccidiosis. Parasite Immunol. 2010:32:590-8.

8. Tewari AK, Maharana BR. Control of poultry coccidiosis: changing trends. J Parasit Dis. 2011;35:10-7.

9. Yin $G$, Lin Q, Wei W, Qin M, Liu X, Suo X, et al. Protective immunity against Eimeria tenella infection in chickens induced by immunization with a recombinant C-terminal derivative of EtIMP1. Vet Immunol Immunopathol. 2014;162:117-21.

10. Liu T, Huang J, Ehsan M, Wang S, Fei H, Zhou Z, et al. Protective immunity against Eimeria maxima induced by vaccines of Em14-3-3 antigen. Vet Parasitol. 2018;253:79-86.

11. Meunier M, Chemaly M, Dory D. DNA vaccination of poultry: the current status in 2015. Vaccine. 2016;34:202-11.

12. Song X, Zhao X, Xu L, Yan R, Li X. Immune protection duration and efficacy stability of DNA vaccine encoding Eimeria tenella TA4 and chicken IL-2 against coccidiosis. Res Vet Sci. 2017;111:31-5.

13. Vermeulen AN. Progress in recombinant vaccine development against coccidiosis. A review and prospects into the next millennium. Int J Parasitol. 1998;28:1121-30.

14. Zhang B, Yuan C, Song $X$, Xu L, Yan R, Shah M, et al. Optimization of immunization procedure for Eimeria tenella DNA vaccine pVAX1-pEtK2IL-2 and its stability. Acta Parasitol. 2019;64:745-52.

15. Huang Y, Ruan X, Li L, Zeng M. Prevalence of Eimeria species in domestic chickens in Anhui province, China. J Parasit Dis. 2017;41:1014-9.

16. Ogedengbe JD, Hunter DB, Barta JR. Molecular identification of Eimeria species infecting market-age meat chickens in commercial flocks in Ontario. Vet Parasitol. 2011;178:350-4.

17. Barrett J, Jefferies JR, Brophy PM. Parasite proteomics. Parasitol Today. 2000;16:400-3.

18. Suarez-Cortes P, Sharma V, Bertuccini L, Costa G, Bannerman NL, Sannella AR, Williamson $\mathrm{K}$, et al. Comparative proteomics and functional analysis reveal a role of Plasmodium falciparum osmiophilic bodies in malaria parasite transmission. Mol Cell Proteom. 2016;15:3243-55.

19. de Venevelles P, Chich JF, Faigle W, Loew D, Labbe M, Girard-Misguich F, et al. Towards a reference map of Eimeria tenella sporozoite proteins by two-dimensional electrophoresis and mass spectrometry. Int J Parasitol. 2004:34:1321-31

20. Liu L, Xu L, Yan F, Yan R, Song $X$, Li X. Immunoproteomic analysis of the second-generation merozoite proteins of Eimeria tenella. Vet Parasitol. 2009:164:173-82

21. Zhang Z, Wang S, Li C, Liu L. Immunoproteomic analysis of the protein repertoire of unsporulated Eimeria tenella oocysts. Parasite. 2017:24:48. 
22. Song X, Ren Z, Yan R, Xu L, Li X. Induction of protective immunity against Eimeria tenella, Eimeria necatrix, Eimeria maxima and Eimeria acervulina infections using multivalent epitope DNA vaccines. Vaccine 2015;33:2764-70.

23. Tomley F. Techniques for isolation and characterization of apical organelles from Eimeria tenella sporozoites. Methods. 1997;13:171-6.

24. Huang J, Zhang Z, Li M, Song X, Yan R, Xu L, et al. Eimeria maxima microneme protein 2 delivered as DNA vaccine and recombinant protein induces immunity against experimental homogenous challenge. Parasitol Int. 2015;64:408-16.

25. Zhang Z, Huang J, Li M, Sui Y, Wang S, Liu L, et al. Identification and molecular characterization of microneme 5 of Eimeria acervulina. PLoS ONE. 2014;9:e115411.

26. Wu J, Wang F, Gong Y, Li D, Sha J, Huang $X$, et al. Proteomic analysis of changes induced by nonylphenol in Sprague-Dawley rat Sertoli cells. Chem Res Toxicol. 2009;22:668-75.

27. Zhu YF, Cui YG, Guo XJ, Wang L, Bi Y, Hu YQ, et al. Proteomic analysis of effect of hyperthermia on spermatogenesis in adult male mice. J Proteome Res. 2006;5:2217-25.

28. Eckert J, Braun R, Shirley MW. COST 89/820: biotechnology: quidelines on techniques in coccidiosis research. Luxembourg: Office for Official Publications of the European Communities; 1995.

29. Constantinoiu CC, Molloy JB, Jorgensen WK, Coleman GT. Development and validation of an ELISA for detecting antibodies to Eimeria tenella in chickens. Vet Parasitol. 2007;150:306-13.

30. Liu L, Huang X, Liu J, Li W, Ji Y, Tian D, et al. Identification of common immunodominant antigens of Eimeria tenella, Eimeria acervulina and Eimeria maxima by immunoproteomic analysis. Oncotarget. 2017:8:34935

31. Wang Y, Yang L, Xu H, Li Q, Ma Z, Chu C. Differential proteomic analysis of proteins in wheat spikes induced by Fusarium graminearum. Proteomics. 2005;5:4496-503.

32. Chapman HD. Milestones in avian coccidiosis research: a review. Poultry Sci. 2014;93:501-11.

33. Talebi A. Protein profiles of five avian Eimeria species. Avian Pathol. 1995;24:731-5.

34. Constantinoiu CC, Lillehoj HS, Matsubayashi M, Hosoda Y, Tani H, Matsuda $\mathrm{H}$, et al. Analysis of cross-reactivity of five new chicken monoclonal antibodies which recognize the apical complex of Eimeria using confocal laser immunofluorescence assay. Vet Parasitol. 2003;118:29-35.

35. Liu J, Liu L, Li L, Tian D, Li W, Xu L, et al. Protective immunity induced by Eimeria common antigen 14-3-3 against Eimeria tenella, Eimeria acervulina and Eimeria maxima. BMC Vet Res. 2018;14:337.

36. Sahoo MK, Sisodia BS, Dixit S, Joseph SK, Gaur RL, Verma SK, et al. Immunization with inflammatory proteome of Brugia malayi adult worm induces a Th1/Th2-immune response and confers protection against the filarial infection. Vaccine. 2009;27:4263-71.
37. Kamali AN, Marin-Garcia P, Azcarate IG, Diez A, Puyet A, Bautista JM. Plasmodium yoelii blood-stage antigens newly identified by immunoaffinity using purified lgG antibodies from malaria-resistant mice. Immunobiology. 2012;217:823-30.

38. Wang $X$, Wang $X$, Zhang H, Lv M, Zuo T, Wu H, et al. Interactions between HIV-1 Vif and human ElonginB-ElonginC are important for CBF-beta binding to Vif. Retrovirology. 2013:10:94.

39. Luo S, Hoffmann R, Skerka C, Zipfel PF. Glycerol-3-phosphate dehydrogenase 2 is a novel factor $\mathrm{H}$-, factor $\mathrm{H}$-like protein 1-, and plasminogen-binding surface protein of Candida albicans. J Infect Dis. 2013;207:594-603.

40. Amerizadeh A, Khoo BY, Teh AY, Golkar M, Abdul Kl, Osman S, et al. Identification and real-time expression analysis of selected Toxoplasma gondii in-vivo induced antigens recognized by $\lg \mathrm{G}$ and $\lg \mathrm{M}$ in sera of acute toxoplasmosis patients. BMC Infect Dis. 2013;13:287.

41. Tian L, Li W, Huang X, Tian D, Liu J, Yang $X$, et al. Protective efficacy of coccidial common antigen glyceraldehyde 3-phosphate dehydrogenase (GAPDH) against challenge with three Eimeria species. Front Microbiol. 2017:8:1245.

42. Cha SJ, Kim MS, Pandey A, Jacobs-Lorena M. Identification of GAPDH on the surface of Plasmodium sporozoites as a new candidate for targeting malaria liver invasion. J Exp Med. 2016;213:2099-112.

43. Wang W, Jeffery CJ. An analysis of surface proteomics results reveals novel candidates for intracellular/surface moonlighting proteins in bacteria. Mol Biosyst. 2016;12:1420-31.

44. Huard RC, Chitale S, Leung M, Lazzarini LC, Zhu H, Shashkina E, et al. The Mycobacterium tuberculosis complex-restricted gene cfp32 encodes an expressed protein that is detectable in tuberculosis patients and is positively correlated with pulmonary interleukin-10. Infect Immun. 2003;71:6871-83

45. Jeffery CJ. Protein moonlighting: what is it, and why is it important? Philos T R Soc B. 2018. https://doi.org/10.1098/rstb.2016.0523.

46. Min KW, Lee SH, Baek SJ. Moonlighting proteins in cancer. Cancer Lett. 2016;370:108-16.

\section{Publisher's Note}

Springer Nature remains neutral with regard to jurisdictional claims in published maps and institutional affiliations.
Ready to submit your research? Choose BMC and benefit from:

- fast, convenient online submission

- thorough peer review by experienced researchers in your field

- rapid publication on acceptance

- support for research data, including large and complex data types

- gold Open Access which fosters wider collaboration and increased citations

- maximum visibility for your research: over 100M website views per year

At BMC, research is always in progress.

Learn more biomedcentral.com/submissions 